\title{
CORRELATION OF HIGH LEVELS OF ANTIBODIES TO MULTIPLE PRE-ERYTHROCYTIC PLASMODIUM FALCIPARUM ANTIGENS AND PROTECTION FROM INFECTION
}

\author{
CHANDY C. JOHN,* ANN M. MOORMANN, DANIEL C. PREGIBON, PETER ODADA SUMBA, MARILYN M. MCHUGH, \\ DAVID L. NARUM, DAVID E. LANAR, MARK D. SCHLUCHTER, AND JAMES W. KAZURA \\ Center for Global Health and Diseases, Rainbow Center for International Child Health, Division of Pediatric Infectious Diseases, \\ Division of Clinical Epidemiology, Rainbow Babies and Children's Hospital, Case Western Reserve University, Cleveland, Ohio; \\ Kenya Medical Research Institute, Kisian, Kenya; National Institutes of Health, Bethesda, Maryland; Walter Reed Army Institute for \\ Research, Washington, District of Columbia
}

\begin{abstract}
High levels of antibodies to multiple antigens may be more strongly associated with protection from infection than antibodies to a single antigen. Antibody-associated protection against Plasmodium falciparum infection was assessed in a cohort of 68 adults living in an area of holoendemic malaria in Kenya. Antibodies to the preerythrocytic antigens circumsporozoite protein (CSP), liver-stage antigen-1 (LSA-1), thrombospondin-related adhesive protein (TRAP), and blood-stage antigens apical membrane antigen-1 (AMA-1), erythrocyte binding antigen-175 (EBA-175), and merozoite surface protein 1 (MSP-1) were tested. Peptides were used for CSP (NANP repeat) and LSA-1 (central repeat), and recombinant antigens were used for TRAP (aa $\left.\mathrm{D}_{48}-\mathrm{K}_{394}\right)$, AMA-1 (ectodomain, nonglycosylated), EBA-175 (non-glycosylated), and MSP-1 (MSP-1 19 ). Weekly microscopy testing for P. falciparum infection was performed over a 12-week period after drug-mediated clearance of $P$. falciparum parasitemia. Individuals with high levels of IgG antibodies (> 2 arbitrary units) to CSP, LSA-1, and TRAP had a 57\% decrease in the risk of infection $(95 \%$ confidence interval $=20-77 \%, P=0.016)$. This decreased risk remained significant after adjustment for age, prior parasitemia, bed net use, sickle cell trait, and village of residence. In contrast, protection against infection did not correlate with high levels of IgG antibodies to blood-stage antigens or IgM antibodies to pre-erythrocytic or blood-stage antigens. High levels of IgG antibodies to CSP, LSA-1, and TRAP may be useful immune correlates of protection against $P$. falciparum infection in malaria-endemic populations.
\end{abstract}

\section{INTRODUCTION}

Identification of reliable and reproducible immune correlates of protection against Plasmodium falciparum infection will be important in the development and testing of malaria vaccines. Results from studies of rodent malaria models and humans with partial immunity induced by irradiated sporozoites or repeated natural infections suggest that both antibody and cytokine responses to pre-erythrocytic antigens contribute to or correlate with protection against $P$. falciparum infection. ${ }^{1-7}$ However, neither antibody nor cytokine responses to circumsporozoite protein (CSP) correlated with protection against $P$. falciparum infection in malaria-naive volunteers immunized with the RTS,S CSP vaccine. ${ }^{8,9}$ The identification of immune correlates of protection that can be used to evaluate vaccine immunogenicity and efficacy in populations where malaria is endemic presents additional challenges. First, most individuals will have pre-existing immune responses to multiple pre-erythrocytic antigens. Second, the time at which and number of sporozoites to which an individual has been exposed cannot be controlled. Third, immune responses and partial resistance to blood-stage parasites co-exists in persons who have been repeatedly infected, thus complicating interpretation of endpoints such as the appearance of asexual parasitemia. Despite these constraints, some studies have shown that cytokine responses to pre-erythrocytic antigens such as liver-stage antigen-1 (LSA$1)^{10-14}$ are associated with protection from $P$. falciparum infection in malaria-endemic areas. In addition, a recent study of the RTS,S CSP vaccine in individuals living in a malaria-

\footnotetext{
* Address correspondence to Chandy C. John, Rainbow Center for International Child Health, Rainbow Babies and Children's Hospital, RBC 487, Case Western Reserve University, 11100 Euclid Avenue, MS6008, Cleveland, OH 44106. E-mail: chandy.john@case.edu
}

endemic area demonstrated that CD4-mediated interferon- $\gamma$ (IFN- $\gamma$ ) responses to CSP were associated with protection from infection. ${ }^{15}$ In contrast, observations made in some of the same populations have failed to document a correlation of protection with antibodies to LSA- $1^{10,16}$ and circumsporozoite protein (CSP), ${ }^{16}$ although a trend toward protection was seen with antibodies to CSP in the RTS,S vaccine study. ${ }^{15}$ Given that persons living in malaria-holoendemic areas have experienced repeated natural infections since childhood and develop antibody responses to multiple pre-erythrocytic antigens, we hypothesized that the presence of high levels of antibodies to multiple as opposed to single antigens may be a more robust correlate of protection from infection.

In contrast, antibodies to blood-stage antigens, which act primarily on the growth of parasites undergoing growth in red blood cells, would more likely be associated with protection from high-density parasitemia and morbidity. To test this hypothesis, we measured $\mathrm{IgG}$ and $\mathrm{IgM}$ antibodies to six $P$. falciparum vaccine candidate antigens in adults residing in a malaria-holoendemic area of Kenya. High levels of antibodies to these antigens individually and in combination were compared with time and risk of re-infection after clearance of pre-existing blood-stage parasitemia. This study was performed in adults because the high levels of immunity in this population would allow us the best chance to identify robust immune correlates of protection from infection. Knowledge of likely correlates would be very useful in planning such a study in children, who are at the highest risk of complications from malaria. Antigens to which antibodies were tested included the pre-erythrocytic antigens CSP, LSA-1 and thromobospondin related adhesive protein (TRAP) and the blood-stage antigens apical-membrane antigen-1 (AMA-1), erythrocyte-binding antigen-175 (EBA-175), and merozoite surface protein-1 (MSP-1). 


\section{MATERIALS AND METHODS}

Study site and participants. The study was conducted in Kanyawegi, Nyanza Province, Kenya from August to December 2001. The population of Kanyawegi is approximately 3,500 , and it is located in a malaria- endemic region that is considered holoendemic. ${ }^{17}$ All study participants were $\geq 15$ years old (median age $=37.5$ years). Seventy-seven persons (44 women and 33 men) were successfully recruited for the study. Exclusion criteria were pregnancy and use of antimalarial drugs within the previous two weeks. Use of mosquito nets was ascertained for all study participants.

Treatment reinfection study. Recruitment was done after community and individual meetings were held to explain the nature and purpose of the study. Persons agreeing to participate were given quinine (600 mg orally every 8 hours) for five days and doxycyline (100 mg orally every day) for seven days to clear parasitemia. Blood for laboratory studies was obtained by venipuncture prior to anti-malarial treatment. The participants were followed for malaria infection by microscopic inspection of blood smears obtained weekly for 14 weeks by pricking the finger with a lancet. Clearance of parasitemia was documented by microscopy and polymerase chain reaction (PCR) testing two weeks after initial antimalarial administration. Persons who did not clear parasitemia by PCR testing were excluded from further analysis. Time to re-infection was calculated as time to the appearance of blood-stage parasites beginning two weeks after antimalarial drug administration (total follow-up time $=12$ weeks). Individuals who missed more than two weeks of blood smear testing were included in analysis up to the time of their last blood smear.

Blood was obtained immediately from persons who had symptoms of malaria in the follow-up period, and a single dose of sulfadoxine-pyrimethamine $(600 \mathrm{mg}$ of sulfadoxine and $25 \mathrm{mg}$ of pyrimethamine) was given to those with clinical malaria, which was defined as 1) $P$. falciparum infection of any density on blood smear and an axillary temperature $\geq$ $37.5^{\circ} \mathrm{C}$ or a history of fever within the previous 24 hours; or 2) $P$. falciparum parasitemia $\geq 5,000$ parasites/ $\mu \mathrm{L}$ with any malaria symptoms.

Informed consent and ethical approval. Written informed consent was obtained from all participants. Ethical approval for the study was granted by the Kenya Medical Research Institute National Ethical Review Committee and the Institutional Review Board for Human Studies at University Hospitals of Cleveland and Case Western Reserve University.

Microscopy and polymerase chain reaction testing for $\boldsymbol{P}$. falciparum infection and the hemoglobin $\mathrm{S}(\mathrm{HbS})$ mutation (sickle cell trait). Malaria infection was diagnosed by microscopic inspection of thick and thin blood smears as previously described. ${ }^{18}$ Plasmodium falciparum infection was further confirmed by nested PCR amplification of $P$. falciparum $18 \mathrm{~S}$ small subunit RNA as described by Snounou and others. ${ }^{19}$ The HbS mutation was detected by PCR amplification followed by digestion with the restriction enzyme Bsu 361 as described by Husain and others. ${ }^{20}$

Antibody testing by enzyme-linked immunosorbent assay (ELISA). The presence of antibodies to CSP and LSA-1 was tested using central repeat sequence peptides to which individuals from malaria-endemic areas have previously been observed to have $\operatorname{IgG}$ antibodies. The (NANP) $)_{5}$ repeat pep- tide $^{21}$ was used for CSP, and the central amino acid repeat sequence LAKEKLQGQQSDLEQERLAKEKLQ-EQQSDLEQERLAKEKLQ (LSA-Rep) ${ }^{22}$ was used for LSA-1. The presence of antibodies to TRAP, AMA-1, EBA-175 and MSP-1 was tested using recombinant antigens. Recombinant P. falciparum TRAP (3D7) was expressed in Escherichia coli and provided by one of the authors (DEL). The gene fragment encoding amino acids $\mathrm{D}_{48}$ to $\mathrm{K}_{394}$ was PCR-amplified from the 3D7 strain of parasite genomic DNA using genespecific sense and antisense primers. Recombinant AMA-1 (ectodomain, non-glycosylated) and EBA-175 (glycosylated and non-glycosylated) were expressed in Pichia pastoris and provided by one of the authors (DLN). Since antibody levels to glycosylated EBA-175 and non-glycosylated EBA-175 were similar, only the results of antibodies to the nonglycosylated form are reported. Recombinant MSP-1 19 protein corresponding to the E-KNG variant was expressed in Saccharomyces cerivisiae $e^{23}$ and provided by the Malaria Research and Reference Reagent Resource Center (Manassas, VA). In previous testing in this area, $\mathrm{IgG}$ antibodies from adult sera most frequently recognized the E-KNG variant.

IgG antibodies were measured by an ELISA. The CSP and LSA-1 peptides were dissolved in $0.01 \mathrm{M}$ phosphate-buffered saline (PBS) to a concentration of $10 \mu \mathrm{g} / \mathrm{mL}$, and recombinant antigens were dissolved in 0.01 M PBS to concentrations of $0.1 \mu \mathrm{g} / \mathrm{mL}$ (AMA-1 and EBA-175), $0.2 \mu \mathrm{g} / \mathrm{mL}$ (MSP-1), and $0.5 \mu \mathrm{g} / \mathrm{mL}$ (TRAP). Fifty microliters of antigen solution was added to Immulon-4 plates (Dynex Technologies, Chantilly, VA). Following overnight incubation at $4^{\circ} \mathrm{C}$, washing with PBS, $0.05 \%$ Tween 20, and blocking in $5 \%$ (w/v) non-fat powdered milk in PBS, duplicate $50-\mu \mathrm{L}$ samples of serum diluted 1:100 in 5\% powdered milk were added to wells and incubated for two hours at room temperature. After washing with PBS, $0.05 \%$ Tween $20,50 \mu \mathrm{L}$ of alkaline phosphataseconjugated goat anti-human IgG (Jackson ImmunoResearch, West Grove, PA) diluted 1:1,000 in 5\% powdered milk was added and removed after one hour. After extensive washing with PBS, $0.05 \%$ Tween 20, p-nitrophenylphosphate was added in accordance with the manufacturer's instructions (Sigma Chemical Co., St. Louis, MO). Optical density (OD) was measured at $405 \mathrm{~nm}$.

IgG1, IgG2, IgG3, and IgG4 subclass antibodies were measured by ELISA with several adjustments. Phosphatebuffered saline-3\% bovine serum albumin (BSA) was used as blocking solution and PBS-1\% BSA was used as diluent. Mouse anti-human IgG subclass biotinylated antibodies (Zymed Laboratories, San Francisco, CA) diluted 1:1,000 were added after incubation of antigen-coated microtiter wells with human sera and washing with PBS, $0.05 \%$ Tween 20. Plates were washed again with PBS, $0.05 \%$ Tween 20 after a 45-minute incubation at room temperature and streptavidin-conjugated alkaline phosphatase (Jackson ImmunoResearch) diluted 1:2,000 in diluent was added. Plates were washed with PBS, $0.05 \%$ Tween 20 after a 30-minute incubation period and $p$-nitrophenylphosphate was then added and the OD at $405 \mathrm{~nm}$ was measured.

IgM antibodies were tested by ELISA with the following adjustments. Seablock buffer (Pierce Biotechnology, Rockford, IL) was used as blocking buffer and diluent, and goat anti-human alkaline phosphatase-conjugated IgM (Southern Biotech, Birmingham, AL) at a dilution of 1:4,000 was used to detect IgM. 
Antibody levels were expressed in arbitrary units (AU), which are calculated by dividing the OD generated by the test sample by the mean OD plus 3 SD generated by samples from 40 North Americans never exposed to malaria. Sera from 9 North American control subjects with OD values representative of the 40 North American samples initially tested were used on individual plates. Values $\geq 1.0$ AU were considered positive. The OD values for the AU cut-off for IgG antibodies to CSP, LSA-1, TRAP, AMA-1, EBA-175, and MSP-1 were $0.066,0.049,0.130,0.240,0.102$, and 0.029 , respectively. Samples were tested on two days, with positive controls of individuals with known antibodies to these antigens on each plate, and the values of positive controls were similar between days. Mean OD values for positive controls for IgG antibodies to CSP, LSA-1, TRAP, AMA-1, EBA-175, and MSP-1 were $1.49,1.02,0.65,0.86,0.58$, and 1.40 , respectively. To assess if antibody AU correlated with antibody titers, antibody titers $(1: 100-1: 51,200)$ were assessed in all 68 individuals for LSA-1. Correlation between AU and titer for LSA-1 was very strong (Spearman's $\rho=0.76, P<0.0001$ ).

Statistical analysis. Since antibodies to individual antigens were present in up to $87 \%$ of the study participants, time to re-infection was assessed in individuals with high levels of antibodies. The threshold for high levels of antibodies was arbitrarily set at $2 \mathrm{AU}$, or twice the threshold for a positive response. This threshold allowed differentiation of a subset of individuals for each antigen and provided enough numbers with high level of antibodies to all three pre-erythrocytic or blood-stage antigens to allow comparisons between those with and without high levels of antibodies. Since exploration of higher thresholds would have involved multiple comparisons, this was not conducted in the initial analysis.

Correlations between continuous variables, e.g., antibody levels and age, were assessed by Spearman's rank correlation. Associations between categorical variables, e.g., presence of $\mathrm{HbS}$ and antibodies to specific antigens, were assessed by chi-square analysis. Kaplan-Meier survival analysis and the log-rank test were used to compare the time to development of $P$. falciparum parasitemia in study participants with and without high levels of IgG antibodies to individual antigens or to all three pre-erythrocytic or all three blood-stage antigens. Risk of infection was assessed by Cox proportional hazards analysis. Multiple comparisons were adjusted for by the Bonferroni correction. Age, HbS status, bed net use, malaria infection status prior to anti-malarial treatment, and village of residence were adjusted for in the final Cox model. Bed nets were used by $7.4 \%$ of the individuals, and $27.9 \%$ had $\mathrm{HbAS}$ (sickle cell trait). The trial sample size was designed to have
$80 \%$ power to detect a $50 \%$ decrease in infection in individuals with high levels of antibodies, assuming the presence of high level of antibodies in at least one-third of the samples and a cumulative malaria infection incidence $\geq 75 \%$. Statistical analysis was done with Stata 8.0 (Stata Corporation, College Station, TX).

\section{RESULTS}

Infection with $\boldsymbol{P}$. falciparum. Seventy-seven individuals were enrolled in the study. Two weeks after treatment, two individuals had persistent $P$. falciparum blood-stage infection by microscopy testing, and seven additional individuals had persistent infection by PCR testing. Analysis of time to reinfection and risk of infection was performed on the remaining 68 individuals. Twelve individuals $(17.6 \%)$ remained free of blood-stage infection for the entire 12-week follow-up period.

Frequencies and levels of antibodies to $\boldsymbol{P}$. falciparum preerythrocytic and blood-stage antigens. $\mathrm{IgG}$ antibodies to the pre-erythrocytic or blood-stage antigens tested were present in $72-88 \%$ of study participants. Levels of $\mathrm{IgG}$ antibodies to the pre-erythrocytic antigens CSP, LSA-1, and TRAP were generally high (Table 1). High levels of $\operatorname{IgG}$ antibodies (> 2 AU) were present in $60-76 \%$ of the individuals (Table 2). $\mathrm{IgG}$ antibodies to all antigens were almost exclusively of the IgG1 and $\mathrm{IgG} 3$ subclasses. Less than $4 \%$ of all individuals had IgG2 antibodies to any antigen except LSA-1 (16\%). Only $4 \%$ of the participants had IgG4 antibodies to any of the antigens studied. The frequencies of $\operatorname{IgG} 1, \operatorname{IgG} 3$ and $\mathrm{IgM}$ antibodies were more variable than those of $\mathrm{IgG}$ antibodies (Table 1).

IgG antibodies to the various antigens correlated weakly with each other, with the exception of LSA-1 and TRAP (Spearman's $\rho=0.50, P<0.0001$ ). In contrast, IgM antibodies to all of the antigens correlated strongly with each other (Spearman's $\rho=0.58-0.89$, all $P$ values $<0.0001)$. IgM to LSA-1 was more frequent in persons with parasitemia than in those without parasitemia at the beginning of the study ( $85.7 \%$ versus $53.8 \%, P=0.004$, by chi-square test). There was no correlation between blood-stage infection or parasite density prior to the administration of anti-malarial drugs and $\mathrm{IgG}, \mathrm{IgG}$ subclass, or IgM antibodies to any of the antigens tested. Age was also not associated with antibody level to any antigen except CSP, for which IgG, IgG1, and IgG3 antibody levels correlated significantly with age (Spearman's $\rho=0.42$, 0.32 , and $0.33, P=0.003,0.008$, and 0.006 , respectively).

TABLE 1

Antibody frequencies and levels (AU) to Plasmodium falciparum antigens in Kenyan adults*

\begin{tabular}{|c|c|c|c|c|c|c|c|c|}
\hline \multirow[b]{2}{*}{ Antigen } & \multicolumn{2}{|c|}{$\operatorname{IgG}$} & \multicolumn{2}{|c|}{ IgM } & \multicolumn{2}{|c|}{ IgG1 } & \multicolumn{2}{|c|}{ IgG3 } \\
\hline & Frequency & $\begin{array}{l}\text { Median level } \\
\text { (IQR) }\end{array}$ & Frequency & $\begin{array}{c}\text { Median level } \\
\text { (IQR) }\end{array}$ & Frequency & $\begin{array}{c}\text { Median level } \\
(\mathrm{IQR})\end{array}$ & Frequency & $\begin{array}{l}\text { Median level } \\
\text { (IQR) }\end{array}$ \\
\hline CSP & $88 \%$ & $6.38(6.99)$ & $54 \%$ & $1.18(1.73)$ & $46 \%$ & $0.87(1.18)$ & $50 \%$ & $0.98(3.31)$ \\
\hline LSA-1 & $78 \%$ & $4.25(8.14)$ & $74 \%$ & $1.95(3.18)$ & $87 \%$ & $2.61(5.4)$ & $57 \%$ & $1.64(7.2)$ \\
\hline TRAP & $87 \%$ & $3.82(4.15)$ & $28 \%$ & $0.58(0.76)$ & $85 \%$ & $3.27(3.39)$ & $65 \%$ & $1.91(3.26)$ \\
\hline AMA-1 & $88 \%$ & $2.24(3.16)$ & $53 \%$ & 1.15 (1.89) & $90 \%$ & $2.75(2.15)$ & $32 \%$ & $0.51(1.21)$ \\
\hline EBA-175 & $72 \%$ & $3.61(7.52)$ & $25 \%$ & $0.48(0.72)$ & $53 \%$ & $1.17(2.06)$ & $28 \%$ & 0.38 (1.14) \\
\hline MSP-1 & $76 \%$ & $2.78(10.2)$ & $31 \%$ & $0.57(0.75)$ & $62 \%$ & $2.11(5.72)$ & $81 \%$ & $6.23(23.33)$ \\
\hline
\end{tabular}

$1 ;$ TRAP $=$ thrombospondin related adhesive protein; AMA-1 = apical membrane antigen-1; EBA $175=$ erythrocyte-binding antigen $175 ;$ MSP-1 = merozoite surface protein 1. 
TABLE 2

Risk of Plasmodium falciparum infection in adults with high-level IgG antibodies to individual $P$. falciparum antigens*

\begin{tabular}{lcc}
\hline \multicolumn{1}{c}{ Antigen } & Number with AU $>2(\%)$ & Hazard ratio $(95 \% \mathrm{CI}) \dagger$ \\
\hline CSP & $52(76.4)$ & $0.65(0.34,1.27)$ \\
LSA-1 & $46(67.6)$ & $0.70(0.38,1.28)$ \\
TRAP & $49(72.0)$ & $0.72(0.38,1.33)$ \\
AMA-1 & $43(63.2)$ & $0.74(0.41,1.33)$ \\
EBA-175 & $45(66.2)$ & $1.25(0.66,2.36)$ \\
MSP-1 & $41(60.3)$ & $1.27(0.69,2.34)$ \\
\hline
\end{tabular}

* For definitions of abbreviations, see Table 1

$\dagger$ Cox proportional hazards ratio. $\mathrm{CI}=$ confidence interval.

IgG antibodies to pre-erythrocytic and blood-stage antigens and risk of re-infection. Time to and risk of re-infection did not differ significantly for study participants with or without high levels of IgG antibodies to any antigen considered individually (Table 2). When antibody levels were modeled as continuous variables in the Cox model, there were trends toward decreased risk of infection with increasing antibody levels to $\operatorname{CSP}(P=0.09)$ and TRAP $(P=0.17)$. Persons with high levels of $\operatorname{IgG}$ antibodies $(\mathrm{AU}>2)$ to all three of the pre-erythrocytic antigens (CSP, LSA-1, and TRAP), comprising $46 \%$ of the total study participants, had a significantly delayed time to re-infection and decreased risk of infection compared with those without high levels of $\mathrm{IgG}$ to these antigens. Median times to re-infection for individuals with and without high levels of antibodies to CSP, LSA-1, and TRAP were 61 and 38 days, respectively $(P=0.012$, Figure 1$)$, and individuals with high levels of antibodies to CSP, LSA-1, and TRAP had a $57 \%$ decrease in risk of infection $(95 \%$ confidence interval $[\mathrm{CI}]=20-77 \%, P=0.016)$. After adjustment for age, initial $P$. falciparum infection, hemoglobin $\mathrm{S}$ status, use of mosquito nets, and village of residence, risk of infection in individuals with high levels of IgG to CSP, LSA-1, and TRAP remained 55\% lower than in individuals without these antibodies (95\% CI $=9-78 \%, P=0.028)$. High levels of antibodies to any two of the three pre-erythrocytic antigens produced a more modest, non-significant protective effect.

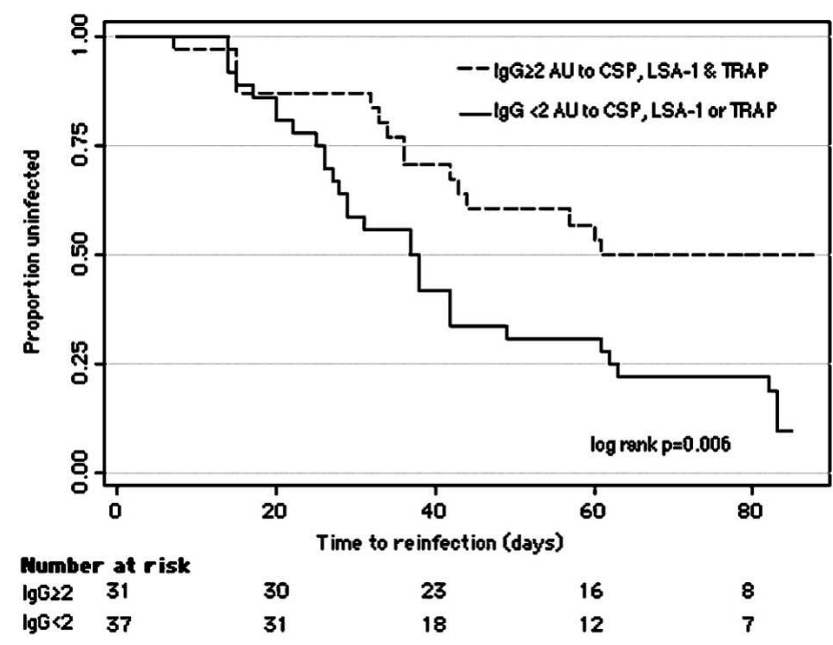

Figure 1. Time to Plasmodium falciparum reinfection in adults with high levels of IgG antibodies to circumsporozoite protein (CSP), liver-stage antigen-1 (LSA-1), and thrombospondin-related adhesive protein (TRAP). Relative risk of infection $=0.43,95 \%$ confidence interval $=0.23-0.80$.
High-density parasitemia ( $>5,000$ parasites/ $\mu \mathrm{L}$ ) developed in $2(6.4 \%)$ of 31 individuals with high levels of $\mathrm{IgG}$ antibodies to CSP, LSA-1, and TRAP, compared with 5 (13.5\%) of 37 individuals without high levels of antibodies to these antigens ( $P=0.34$, by chi-square test). Non-significant trends toward protection from infection were seen for both high levels of IgG1 and IgG3 to CSP, LSA-1, and TRAP after controlling for potential confounding factors (hazard ratio $[\mathrm{HR}]=0.67$, 95\% CI $=0.33-1.34, P=0.25$ and $\mathrm{HR}=0.50,95 \% \mathrm{CI}=$ $0.22-1.15, P=0.10$, respectively).

In contrast, time to re-infection and risk of infection did not differ between groups of individuals with and without high levels of antibodies to the three blood-stage antigens AMA-1, EBA-175, and MSP-1 (Figure 2), although a trend toward a decreased risk of infection was seen was increasing IgG antibody levels to AMA-1 $(P=0.14)$. High-density parasitemia was not different in those with and without high levels of antibodies to blood-stage antigens. IgM antibodies to specific or grouped pre-erythrocytic or blood-stage antigens did not correlate with protection from infection.

\section{DISCUSSION}

The present study demonstrates that high levels of IgG antibodies to multiple pre-erythrocytic antigens are associated with protection against $P$. falciparum infection in adults living in a malaria-holoendemic area. The $57 \%$ reduction in risk of re-infection $(95 \% \mathrm{CI}=20-77 \%)$ seen in Kenyan adults with high levels of $\mathrm{IgG}$ antibodies to the preerythrocytic antigens CSP, LSA-1, and TRAP remained after adjustment for multiple other potentially protective factors. These results provide new evidence that development of high levels of immunity to multiple pre-erythrocytic antigens may be important in protection against $P$. falciparum infection.

Several previous studies have suggested an association between antibodies to pre-erythrocytic antigens and protection against $P$. falciparum infection. Two trials of the CSPcontaining vaccine RTS,S-ASO2 conducted in the Gambia

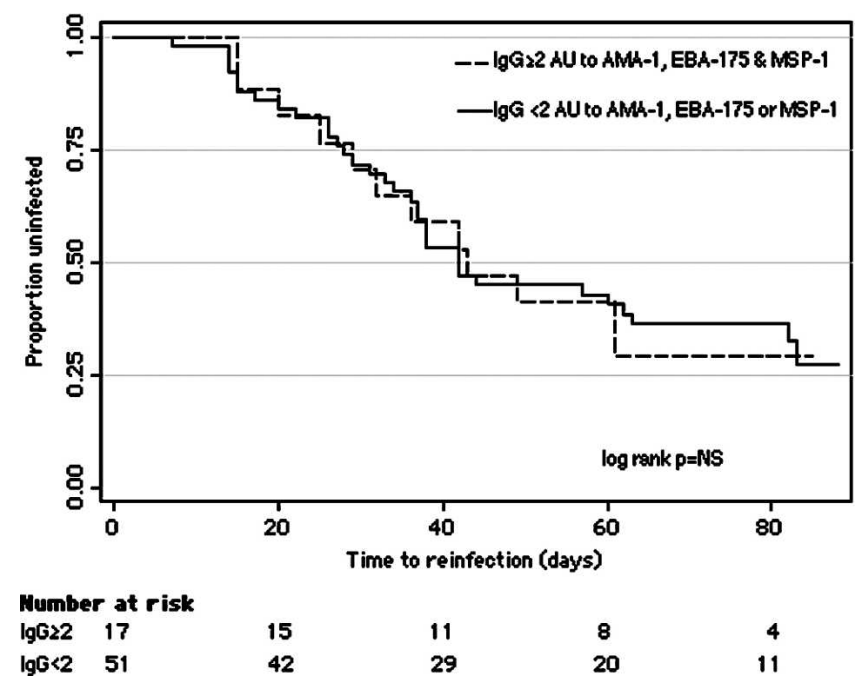

Figure 2. Time to Plasmodium falciparum reinfection in adults with high level of $\operatorname{IgG}$ antibodies to apical membrane antigen-1 (AMA-1), erythrocyte binding antigen-175 (EBA-175), and merozoite surface protein 1 (MSP-1). Relative risk of infection $=1.04,95 \%$ confidence interval $=0.54-2.02$. NS $=$ not significant. 
documented an association or trend between antibodies to CSP and protection against infection. In the first study, a CSP antibody level $>2.7 \mathrm{mg} / \mathrm{L}$ prior to vaccination correlated with a $49 \%$ decrease in risk of infection (95\% CI $=24-66 \%)$ that was independent of vaccination status. ${ }^{24}$ In the second study, a trend toward delayed time to infection was seen in vaccinated individuals with higher antibody levels to CSP, although this did not achieve statistical significance. ${ }^{15}$ In the present study, a similar trend toward decreased infection was seen in individuals with high levels of antibodies to CSP. We chose a fixed AU cut-off level prior to determining association with time to re-infection to avoid generation of spurious associations by multiple comparisons. However, without a reference antibody concentration, we were unable to measure exact concentrations of antibodies to CSP, and the cut-off we chose may have been significantly lower than $2.7 \mathrm{mg} / \mathrm{L}$. Exploratory analysis showed that the choice of a cut-off AU of 3 for CSP was more strongly associated with protection $(P=$ 0.07 ), but cut-offs above this level were not associated with protection. Trends toward protection from infection were seen in individuals with high levels of $\mathrm{IgG} 1$ and $\mathrm{IgG} 3$ subclass antibodies to CSP, LSA-1, and TRAP. The lack of statistical significance for these associations may reflect the smaller numbers of individuals with high levels of subclass antibodies to all three antigens (28 individuals for $\mathrm{IgG} 1$ and 16 individuals for IgG3).

Earlier studies in children also provide evidence that antibodies to LSA-1 and TRAP may be associated with protection from malaria infection and disease. Antibodies to LSA-1 correlated with more rapid parasite clearance time ${ }^{12}$ and protection from clinical malaria ${ }^{25}$ in Gabon, and antibodies to TRAP correlated with a decrease in high-density parasitemia $^{26}$ and decreased infection ${ }^{16}$ in children in other malariaendemic areas of Africa. Observations of adults have not demonstrated a correlation a protection with antibodies to LSA- $1^{10,27}$ or TRAP,${ }^{16}$ but these reports did not examine the presence of high levels of antibodies to multiple preerythrocytic antigens.

Antibodies to pre-erythrocytic antigens may be surrogate markers for other immune processes or, in part, mediate protection against infection. In vitro and in vivo studies demonstrating that antibodies to CSP and TRAP impair or completely prevent infection in murine malaria models ${ }^{2,28,29}$ provide biologic evidence to support the possible causal association of these antibodies with protection. At the same time, it is well established the $\mathrm{T}$ cell responses involving IFN- $\gamma$ and other cytokines mediate protection against liverstage malaria. ${ }^{1,6,30,31}$ It is not possible to evaluate or quantify directly the level of protection directed against liver-stage malaria in humans. IgG antibody levels in the study participants were unrelated to IFN- $\gamma$ or interleukin- 10 responses to TRAP or LSA-1 peptides measured concurrently (John CC, Moormann AM, unpublished data), suggesting that the two processes may be independently regulated in persons with natural infection. One potential mechanism for antibodyrelated protection is the combined effects of antibodies that target different steps during the pre-erythrocytic phase of infection life cycle. Circumsporozoite protein is important in adhesion of the sporozoite to the basolateral membrane of the hepatocyte, ${ }^{32,33}$ and monoclonal antibodies to CSP inhibit parasite invasion of hepatoma cells. ${ }^{28}$ Thrombospondinrelated adhesive protein is essential for sporozoite gliding mo- tility $^{7}$ and hepatocyte invasion, ${ }^{29}$ and antibodies to TRAP have also been shown to prevent sporozoite invasion of hepatocytes. $^{2,4}$ Antibodies to LSA-1 may act to augment antibodydependent cellular inhibition of parasite growth or to increase clearance of liver-stage merozoites just prior to their release into the bloodstream. ${ }^{34}$ In the multi-step process of preerythrocytic infection, antibodies to a single antigen, which inhibit a single step in the infection cycle (e.g., sporozoite attachment via CSP) may be significantly less effective in prevention of infection than antibodies to multiple antigens, which inhibit several sequential steps.

Recent proteomic studies have showed expression in the sporozoite of antigens traditionally considered blood-stage antigens, including var and rif gene variant proteins, ${ }^{35}$ AMA$1,{ }^{35,36}$ and EBA-175. ${ }^{37}$ One study demonstrated that antibodies to AMA-1 blocked sporozoite invasion of hepatocytes, ${ }^{36}$ and, interestingly, in the present study, a trend toward protection from infection was seen with high levels of antibodies to AMA-1, but not to EBA-175 or MSP-1. Several previous studies have demonstrated an association with protection from disease in children with antibodies to MSP-1. ${ }^{38-41}$ The present study was conducted in adults and was a study of protection from infection. We were not able to test protection from disease because too few of the adults in our study developed clinical disease during the study period. The different study population (adults) and clinical endpoint (infection) in our study when compared with prior studies may explain in part why we did not see protection associated with antibodies to MSP-1. Ongoing studies are assessing the relationship of these antibodies to protection from disease in children in this area.

The reasons why certain individuals have high levels of antibodies to all three antigens while others do not remain poorly understood. Exposure levels may be different across the study area, but the association of protection with high levels of antibodies to CSP, TRAP, and LSA-1 remained even after inclusion of village area in a multivariate model. Alternatively, genetic factors or the presence of other infectious diseases or illnesses may alter the ability to develop and maintain such antibodies. Since malaria vaccine programs in holoendemic areas will target children, it will be important to document how such antibody responses develop with age, and to determine whether high levels of antibodies are stable over time in children and adults in this population.

A caveat of this and most studies of antibodies to $P$. falciparum antigens is the lack of standardization of antibody concentrations. Calculation and expression of antibody levels by comparison with reactivity of sera from persons not exposed to malaria, which are inherently subject to variation from one center to the next, were used here. As noted previously, the cut-off level of 2 AU for high levels of antibodies, while clearly reflecting strong responses, was arbitrary. In exploratory analyses done after the initial analysis, we found that for each antigen there was an ideal cut-off value that corresponded best with protection (AU $>2$ for LSA-1, AU $>4$ for TRAP, and AU > 3 for CSP). However, initial assessment using multiple cut-off values would have necessitated multiple comparisons and limited power to detect significant associations. Trends toward delayed risk of infection were seen with higher antibody levels to CSP and TRAP, supporting a doseresponse relationship with protection from infection for these antigens. Arbitrary units assume a continuous linear relation- 
ship between OD at a fixed concentration and antibody titer, and may be an inaccurate for either very low or very high titers. Our titer testing for a single antigen (LSA-1) demonstrated that overall, titers correlated well with AU for this antigen, and for the relatively low AU cut-off $(>2)$ used for high levels in this study, it is unlikely that titer measurement would have made a difference in our assessment. Rigorous comparison of antibody levels and cut-offs in various malariaendemic populations will require use of the same recombinant antigens and development of antibody concentration standards. Widely accepted criteria of the strength of antibody responses to these antigens, the likelihood of their correlation with protection against infection, and greater understanding of the antecedents and modifiers of $\mathrm{IgG}$ antibodies to pre-erythrocytic $P$. falciparum will be valuable in the search for surrogate biomarkers that can used to guide and test malaria vaccines in the field. The present study has provided cut-off values and candidate antigens to assess the protective effect of IgG antibodies in children. Future studies will address whether the high levels of protection from infection associated with these antibodies in adults are seen in children in this area.

Received November 4, 2004. Accepted for publication December 30, 2004.

Acknowledgments: We thank the Kanyawegi site field assistants for their daily follow-up of study participants and Jackson Abuya and Livingstone Wanyama for microscopy evaluation. We also thank the Office of the Director of the Kenya Medical Research Institute for permission to publish this study.

Financial support: This work was supported by grant AI43906 form the U.S. Public Health Service.

Author' addresses: Chandy C. John, Rainbow Center for International Child Health, Rainbow Babies and Children's Hospital, RBC 487, Case Western Reserve University, 11100 Euclid Avenue, MS6008, Cleveland, OH 44106, Telephone: 216-844-3645, Fax: 216844-8362, E-mail: chandy.john@case.edu. Ann M. Moormann, Daniel C. Pregibon, Marilyn M. McHugh, and James W. Kazura, Center for Global Health and Diseases, Case Western Reserve University School of Medicine, 2103 Cornell Road, Room 4128, Wolstein Research Building, Fourth Floor, Cleveland, OH 44106-7286. Telephone: 216-368-4822, Fax: 216-368-4825, E-mails: ann.moormann@ case.edu,pregibon@mit.edu,marilyn.mchugh@case.edu, and james.kazura@case.edu. Peter Odada Sumba, Kenya Medical Research Institute, Box 1576, Kisumu, Kenya, Telephone: 254-05722989, E-mail: pos@case.edu. David L. Narum, Malaria Vaccine Development Branch, National Institutes of Health, Twinbrook I Facility, 5640 Fishers Lane, Rockville, MD 20852, Telephone: 301435-2185, Fax: 301-480-1962, E-mail: dnarum@niaid.nih.gov. David E. Lanar, Department of Immunology, Walter Reed Army Institute of Research, 503 Robert Grant Avenue, Silver Spring, MD 209107500, Telephone: 301-319-9003, Fax: 202-318-7594, E-mail: david. lanar@na.amedd.army.mil. Mark D. Schluchter, Division of Clinical Epidemiology, Department of Pediatrics, Rainbow Babies and Children's Hospital, Case Western Reserve University, 11100 Euclid Avenue, Cleveland, OH 44106-6003, Telephone: 216-844-2391, Fax: 216844-6265, E-mail: mark.schluchter@case.edu.

\section{REFERENCES}

1. Doolan DL, Sedegah M, Hedstrom RC, Hobart P, Charoenvit Y, Hoffman SL, 1996. Circumventing genetic restriction of protection against malaria with multigene DNA immunization: CD8+ cell-, interferon gamma-, and nitric oxide-dependent immunity. J Exp Med 183: 1739-1746.

2. Charoenvit Y, Fallarme V, Rogers W, Sacci JJ, Kaur M, Aguiar J, Yuan L, Corradin G, Andersen E, Wizel B, Houghten R,
Oloo A, De IVP, Hoffman S, 1997. Development of two monoclonal antibodies against Plasmodium falciparum sporozoite surface protein 2 and mapping of B-cell epitopes. Infect Immun 65: $3430-3437$.

3. Egan J, Hoffman S, Haynes J, Sadoff J, Schneider I, Grau G, Hollingdale M, Ballou W, Gordon D, 1993. Humoral immune responses in volunteers immunized with irradiated Plasmodium falciparum sporozoites. Am J Trop Med Hyg 49: 166-173.

4. Muller HM, Scarselli E, Crisanti A, 1993. Thrombospondin related anonymous protein (TRAP) of Plasmodium falciparum in parasite-host cell interactions. Parassitologia 35 (Suppl): 6972.

5. Potocnjak P, Yoshida N, Nussenzweig R, Nussenzweig V, 1980. Monovalent fragments (Fab) of monoclonal antibodies to a sporozoite surface antigen $(\mathrm{Pb} 44)$ protect mice against malarial infection. J Exp Med 151: 1504-1513.

6. Sedegah M, Hedstrom R, Hobart P, Hoffman S, 1994. Protection against malaria by immunization with plasmid DNA encoding circumsporozoite protein. Proc Natl Acad Sci U S A 91: 98669870.

7. Sultan AA, 1999. Molecular mechanisms of malaria sporozoite motility and invasion of host cells. Int Microbiol 2: 155-160.

8. Stoute JA, Kester KE, Krzych U, Wellde BT, Hall T, White K, Glenn G, Ockenhouse CF, Garcon N, Schwenk R, Lanar DE, Sun P, Momin P, Wirtz RA, Golenda C, Slaoui M, Wortmann G, Holland C, Dowler M, Cohen J, Ballou WR, 1998. Longterm efficacy and immune responses following immunization with the RTS,S malaria vaccine. J Infect Dis 178: 1139-1144.

9. Stoute JA, Slaoui M, Heppner DG, Momin P, Kester KE, Desmons P, Wellde BT, Garcon N, Krzych U, Marchand M, 1997. A preliminary evaluation of a recombinant circumsporozoite protein vaccine against Plasmodium falciparum malaria. RTS,S Malaria Vaccine Evaluation Group. N Engl J Med 336: 86-91.

10. Kurtis JD, Lanar DE, Opollo M, Duffy PE, 1999. Interleukin-10 responses to liver-stage antigen 1 predict human resistance to Plasmodium falciparum. Infect Immun 67: 3424-3429.

11. Luty AJ, Lell B, Schmidt-Ott R, Lehman LG, Luckner D, Greve B, Matousek P, Herbich K, Schmid D, Migot-Nabias F, Deloron P, Nussenzweig RS, Kremsner PG, 1999. Interferongamma responses are associated with resistance to reinfection with Plasmodium falciparum in young African children. $J$ Infect Dis 179: 980-988.

12. Luty AJ, Lell B, Schmidt-Ott R, Lehman LG, Luckner D, Greve B, Matousek P, Herbich K, Schmid D, Ulbert S, Migot-Nabias F, Dubois B, Deloron P, Kremsner PG, 1998. Parasite antigenspecific interleukin-10 and antibody reponses predict accelerated parasite clearance in Plasmodium falciparum malaria. Eur Cytokine Netw 9: 639-646.

13. Connelly M, King CL, Bucci K, Walters S, Genton B, Alpers MP, Hollingdale M, Kazura JW, 1997. T-cell immunity to peptide epitopes of liver-stage antigen 1 in an area of Papua New Guinea in which malaria is holoendemic. Infect Immun 65: $5082-5087$.

14. John CC, Sumba PO, Ouma JH, Nahlen BL, King CL, Kazura JW, 2000. Cytokine responses to Plasmodium falciparum liverstage antigen 1 vary in rainy and dry seasons in highland Kenya. Infect Immun 68: 5198-5204.

15. Reece WH, Pinder M, Gothard PK, Milligan P, Bojang K, Doherty T, Plebanski M, Akinwunmi P, Everaere S, Watkins KR, Voss G, Tornieporth N, Alloueche A, Greenwood BM, Kester KE, McAdam KP, Cohen J, Hill AV, 2004. A CD4(+) T-cell immune response to a conserved epitope in the circumsporozoite protein correlates with protection from natural Plasmodium falciparum infection and disease. Nat Med 10: 406-410.

16. John CC, Zickafoose JS, Sumba PO, King CL, Kazura JW, 2003. Antibodies to the Plasmodium falciparum antigens circumsporozoite protein, thrombospondin-related adhesive protein, and liver-stage antigen 1 vary by ages of subjects and by season in a highland area of Kenya. Infect Immun 71: 4320-4325.

17. John CC, Moormann AM, Sumba PO, Ofulla AV, Pregibon DC, Kazura JW, 2004. Gamma interferon responses to Plasmodium falciparum liver-stage antigen 1 and thrombospondin-related adhesive protein and their relationship to age, transmission 
intensity, and protection against malaria. Infect Immun 72: $5135-5142$.

18. John CC, O'Donnell RA, Sumba PO, Moormann AM, de Koning-Ward TF, King CL, Kazura JW, Crabb BS, 2004. Evidence that invasion-inhibitory antibodies specific for the $19-\mathrm{kDa}$ fragment of merozoite surface protein-1 (MSP-1 19) can play a protective role against blood-stage Plasmodium falciparum infection in individuals in a malaria endemic area of Africa. $J$ Immunol 173: 666-672.

19. Snounou G, Viriyakosol S, Jarra W, Thaithong S, Brown KN, 1993. Identification of the four human malaria parasite species in field samples by the polymerase chain reaction and detection of a high prevalence of mixed infections. Mol Biochem Parasitol 58: 283-292.

20. Husain SM, Kalavathi P, Anandaraj MP, 1995. Analysis of sickle cell gene using polymerase chain reaction and restriction enzyme Bsu 361. Indian J Med Res 101: 273-276.

21. Chougnet C, Lepers J, Astagneau P, Rason M, Savel J, Deloron $\mathrm{P}, 1991$. Lymphoproliferative responses to synthetic peptides from merozoite ring-infected erythrocyte surface antigen and circumsporozoite protein: a longitudinal study during a falciparum malaria episode. Am J Trop Med Hyg 45: 560-566.

22. Fidock DA, Gras-Masse H, Lepers JP, Brahimi K, Benmohamed L, Mellouk S, Guerin-Marchand C, Londono A, Raharimalala L, Meis JF, Langsley G, Roussilhon C, Tartar A, Druilhe P, 1994. Plasmodium falciparum liver stage antigen-1 is well conserved and contains potent B and T cell determinants. $J$ Immunol 153: 190-204.

23. Kaslow DC, Hui G, Kumar S, 1994. Expression and antigenicity of Plasmodium falciparum major merozoite surface protein (MSP1(19)) variants secreted from Saccharomyces cerevisiae. Mol Biochem Parasitol 63: 283-289.

24. Bojang KA, Milligan PJ, Pinder M, Vigneron L, Alloueche A, Kester KE, Ballou WR, Conway DJ, Reece WH, Gothard P, Yamuah L, Delchambre M, Voss G, Greenwood BM, Hill A, McAdam KP, Tornieporth N, Cohen JD, Doherty T, 2001. Efficacy of RTS,S/AS02 malaria vaccine against Plasmodium falciparum infection in semi-immune adult men in The Gambia: a randomised trial. Lancet 358: 1927-1934.

25. Migot-Nabias F, Deloron P, Ringwald P, Dubois B, Mayombo J, Minh TN, Fievet N, Millet P, Luty A, 2000. Immune response to Plasmodium falciparum liver stage antigen-1: geographical variations within central Africa and their relationship with protection from clinical malaria. Trans $R$ Soc Trop Med Hyg 94: $557-562$.

26. Scarselli E, Tolle R, Koita O, Diallo M, Muller H, Fruh K, Doumbo O, Crisanti A, Bujard H, 1993. Analysis of the human antibody response to thrombospondin-related anonymous protein of Plasmodium falciparum. Infect Immun 61: 3490-3495.

27. John CC, Ouma JH, Sumba PO, Hollingdale MR, Kazura JW, King CL, 2002. Lymphocyte proliferation and antibody responses to Plasmodium falciparum liver-stage antigen-1 in a highland area of Kenya with seasonal variation in malaria transmission. Am J Trop Med Hyg 66: 372-378.

28. Chatterjee S, Wery M, Sharma P, Chauhan VS, 1995. A conserved peptide sequence of the Plasmodium falciparum circumsporozoite protein and antipeptide antibodies inhibit Plasmodium berghei sporozoite invasion of Hep-G2 cells and protect immunized mice against $\mathrm{P}$. berghei sporozoite challenge. Infect Immun 63: 4375-4381.

29. Muller H, Reckmann I, Hollingdale M, Bujard H, Robson K, Crisanti A, 1993. Thrombospondin related anonymous protein (TRAP) of Plasmodium falciparum binds specifically to sulfated glycoconjugates and to HepG2 hepatoma cells suggesting a role for this molecule in sporozoite invasion of hepatocytes. EMBO J 12: 2881-2889.

30. Doolan DL, Hoffman SL, 2000. The complexity of protective immunity against liver-stage malaria. J Immunol 165: 14531462.

31. Charoenvit Y, Majam VF, Corradin G, Sacci JB Jr, Wang R, Doolan DL, Jones TR, Abot E, Patarroyo ME, Guzman F, Hoffman SL, 1999. CD4(+) T-cell- and gamma interferondependent protection against murine malaria by immunization with linear synthetic peptides from a Plasmodium yoelii 17 kilodalton hepatocyte erythrocyte protein. Infect Immun 67: 5604-5614.

32. Cerami C, Kwakye-Berko F, Nussenzweig V, 1992. Binding of malarial circumsporozoite protein to sulfatides [Gal(3SO4)beta 1-Cer] and cholesterol-3-sulfate and its dependence on disulfide bond formation between cysteines in region II. Mol Biochem Parasitol 54: 1-12.

33. Frevert U, Sinnis P, Cerami C, Shreffler W, Takacs B, Nussenzweig V, 1993. Malaria circumsporozoite protein binds to heparan sulfate proteoglycans associated with the surface membrane of hepatocytes. J Exp Med 177: 1287-1298.

34. Kurtis JD, Hollingdale MR, Luty AJ, Lanar DE, Krzych U, Duffy PE, 2001. Pre-erythrocytic immunity to Plasmodium falciparum: the case for an LSA-1 vaccine. Trends Parasitol 17: 219-223.

35. Florens L, Washburn MP, Raine JD, Anthony RM, Grainger M, Haynes JD, Moch JK, Muster N, Sacci JB, Tabb DL, Witney AA, Wolters D, Wu Y, Gardner MJ, Holder AA, Sinden RE, Yates JR, Carucci DJ, 2002. A proteomic view of the Plasmodium falciparum life cycle. Nature 419: 520-526.

36. Silvie O, Franetich JF, Charrin S, Mueller MS, Siau A, Bodescot M, Rubinstein E, Hannoun L, Charoenvit Y, Kocken $\mathrm{CH}$, Thomas AW, van Gemert GJ, Sauerwein RW, Blackman MJ, Anders RF, Pluschke G, Mazier D, 2004. A role for apical membrane antigen 1 during invasion of hepatocytes by Plasmodium falciparum sporozoites. J Biol Chem 279: 9490-9496.

37. Gruner AC, Brahimi K, Letourneur F, Renia L, Eling W, Snounou G, Druilhe P, 2001. Expression of the erythrocytebinding antigen 175 in sporozoites and in liver stages of Plasmodium falciparum. J Infect Dis 184: 892-897.

38. Branch OH, Udhayakumar V, Hightower AW, Oloo AJ, Hawley WA, Nahlen BL, Bloland PB, Kaslow DC, Lal AA, 1998. A longitudinal investigation of $\mathrm{IgG}$ and $\mathrm{IgM}$ antibody responses to the merozoite surface protein-1 19-kiloDalton domain of Plasmodium falciparum in pregnant women and infants: associations with febrile illness, parasitemia, and anemia. Am J Trop Med Hyg 58: 211-219.

39. Cavanagh DR, Dodoo D, Hviid L, Kurtzhals JA, Theander TG, Akanmori BD, Polley S, Conway DJ, Koram K, McBride JS, 2004. Antibodies to the N-terminal block 2 of Plasmodium falciparum merozoite surface protein 1 are associated with protection against clinical malaria. Infect Immun 72: 64926502.

40. Egan A, Morris J, Barnish G, Allen S, Greenwood B, Kaslow D, Holder A, Riley E, 1996. Clinical immunity to Plasmodium falciparum malaria is associated with serum antibodies to the 19-kDa C-terminal fragment of the merozoite surface antigen, PfMSP-1. J Infect Dis 173: 765-769.

41. Perraut R, Marrama L, Diouf B, Sokhna C, Tall A, Nabeth P, Trape JF, Longacre S, Mercereau-Puijalon O, 2005. Antibodies to the conserved C-terminal domain of the Plasmodium falciparum merozoite surface protein 1 and to the merozoite extract and their relationship with in vitro inhibitory antibodies and protection against clinical malaria in a Senegalese village. J Infect Dis 191: 264-271. 